\title{
Histological and immunohistochemical study of composite neuroendocrine-exocrine carcinomas of the stomach
}

\author{
Nasim Rayhan, Toshiaki Sano, Zhi Rong Qian, Abdul Kader Obari, and Mitsuyoshi Hirokawa \\ Department of Human Pathology, Institute of Health Biosciences, The University of Tokushima Graduate \\ School, Tokushima, Japan
}

\begin{abstract}
Composite neuroendocrine-exocrine carcinomas (NEECs) with two distinct components of adenocarcinoma and neuroendocrine (NE) carcinoma within the same tumor are rare but may have a clue for clarifying the pathogenesis of NE tumors arising from non-endocrine organs. This study was done to characterize histological and immunohistochemical features of NEECs of the stomach comparing with pure NE tumors of the gastrointestinal (GI) tract. Microscopically, adenocarcinoma components in 6 of 8 NEECs were well differentiated and located superficially, whereas NE components were poorly differentiated and located deeply. In the remaining two cases, smaller NE components were intermingled within adenocarcinoma components. Immunohistochemically, neural cell adhesion molecule (NCAM) was positive in 5 NE components, of which 3 cases were homogeneously positive, and 2 adenocarcinoma components of 8 NEECs, while 19 of 21 pure NE tumors of GI tract were homogeneously positive for NCAM. Ghrelinimmunoreactivity was found in $4 \mathrm{NE}$ components and 2 adenocarcinoma components of NEECs, although 20 pure NE tumors were positive for ghrelin. Smad4 was positive in both components of 7 NEECs. These findings suggest that composite NEECs and pure NE tumors of GI tract may have different NE properties and that most NE components of composite NEECs of the stomach may originate from an adenocarcinoma precursor cell and occasional tumors from a pluripotent cell. J. Med. Invest. 52 : 191-202, August, 2005
\end{abstract}

Keywords : composite neuroendocrine-exocrine carcinoma, stomach, NCAM, immunohistochemistry, tumorigenesis

\section{INTRODUCTION}

Neuroendocrine (NE) tumor is a generic term describing any neoplasm with NE differentiation in the vast majority of the tumor cells (1). According to the World Health Organization (WHO) classification, these "typical or pure" NE tumors arising in the gastrointestinal (GI) tract have been classified into well differentiated NE tumors (WDNETs), well differentiated NE carcinomas (WDNECs), and poorly differentiated NE carcinomas (PDNECs) (2). In addition, a recent systematic application of various modern techniques

Received for publication May 31, 2005 ; accepted July 4, 2005.

Address correspondence and reprint requests to Toshiaki Sano, M.D., Ph.D., Department of Human Pathology, Institute of Health Biosciences, The University of Tokushima Graduate School, Kuramotocho, Tokushima 770-8503, Japan, and Fax : +81-88-633-9423. to the pathologic study of GI tract tumors has made a progressive recognition of frequent presence of $\mathrm{NE}$ cells/components in the non-endocrine tumors. Morphologic, ultrastructural and immunohistochemical studies have shown that a continuous spectrum of GI tract tumors exists, ranging from classical adenocarcinomas or adenomas at one end, through various types of mixed exocrine-NE tumors, to typical NE tumors on other end (3).

Gastric epithelial tumors composed of exocrine cells and NE cells can be divided into two broad groups ; 1) adenoma or adenocarcinoma with interspersed $\mathrm{NE}$ cells (4-6) and 2) mixed exocrine-NE tumors, in which $\mathrm{NE}$ components represent at least one-third to half of the tumor tissue, either intimately and diffusely admixed with the non-NE components termed "combined tumors" or occurring in separate areas of the same 
tumors termed "composite tumors" (3). Lewin also classified mixed exocrine-NE tumors as 1) mixed (composite) glandular-endocrine tumors, 2) amphicrine tumors, and 3) collision tumors (1). Gastric composite NE-exocrine carcinomas (NEECs), where two histologically different tissues, adenocarcinoma and $\mathrm{NE}$ carcinoma, are found in juxtaposition to each other in the same tumor, are rare (7-12) and our interest was addressed in this type of tumors. The histogenesis and biological behavior of composite NEECs are still remaining unknown, but these tumors are unique because they may have a clue for clarifying the pathogenesis of NE tumors arising from the non-endocrine organs.

This study was done to characterize histological features and NE properties of composite NEECs of the stomach by use of immunohistochemistry, which included neural cell adhesion molecule (NCAM) that has been known to be expressed in NE tissues and tumors and to have a potential role in tumorigenesis of some tumors (13-15), ghrelin which is a novel peptide in the stomach and has been shown to be expressed in well differentiated NE tumors of the GI tract but not in poorly differentiated $\mathrm{NE}$ carcinomas $(16,17)$, and Smad4 (also known as DPC4) which has been known to be involved in the tumorigenesis of adenocarcinomas and NE tumors of the pancreas and GI tract (18-22). We analyzed the expression of these substances in composite NEECs of the stomach and pure NE tumors arising in the GI tract.

\section{MATERIALS AND METHODS}

\section{Materials}

From the register of surgical pathology files of the Department of Human Pathology, The University of Tokushima Graduate School and affiliated hospitals, we surveyed for NE tumors arising from the GI tract. Total 29 NE tumors were retrieved. In addition, we included one case of composite NEEC arising in the gallbladder because it had all the criteria of composite NEEC. All 30 tumors were fixed with $10 \%$ formalin and embedded in paraffin immediately after resection. Four $\mu \mathrm{m}$-thick sections were cut from each block and mounted on glass slides. They were then stained with hematoxylin and eosin and evaluated for the histological classification of the lesions according to the standard criteria of WHO classification (2).

NE tumors of the GI tract were divided into two groups ; 1) composite NEECs : those tumors consisted of both NE and adenocarcinoma components juxtaposed within each individual tumor and the NE com-

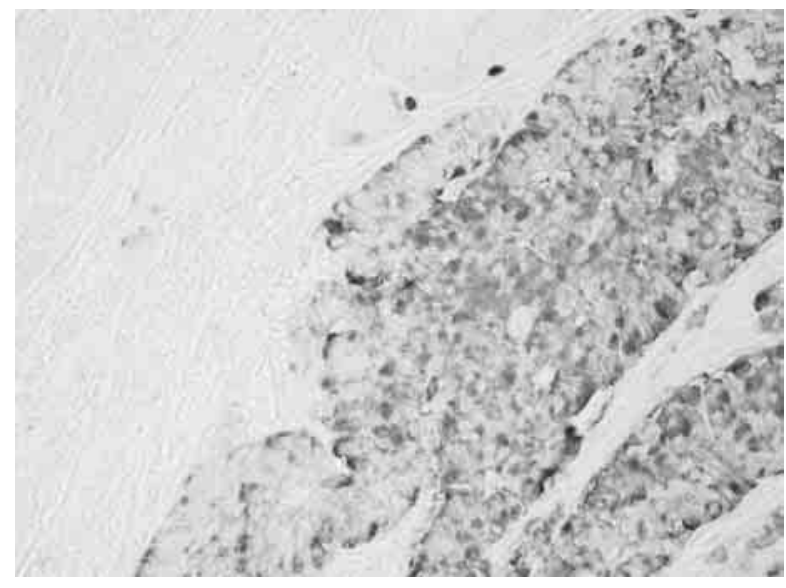

Fig.1. Chromogranin A (CgA) immunostaining of composite NEEC (Case1). Most tumor cells in NE component are immunoreactive for $\mathrm{CgA}$ at right side of the photograph and only a few $\mathrm{CgA}$ positive cells in adenocarcinoma component at left.

ponents occupied at least $30 \%$ of the tumor tissue, and 2) pure NE tumors : those tumors exclusively consisted of NE tissues. Eight composite NEECs were found and all of them were localized in the stomach and 21 pure NE tumors were from various sites of the GI tract. NE components of composite NEECs and pure NE tumors in this study showed chromogranin $\mathrm{A}(\mathrm{CgA})$ - and/or synaptophysin-immunoreactivity in a substantial number of tumor cells (Fig. 1). Clinical data were collected from the medical reports.

\section{Immunohistochemistry}

NCAM, ghrelin and Smad4 immunostainings were performed based on the labeled streptavidin biotin complex (LSAB) method by use of the LSAB kit (Dako Corp., Denmark). After deparaffinization and antigen retrieval using the autoclave technique, the sections were incubated at $4^{\circ} \mathrm{C}$ overnight with primary antibodies : monoclonal antibodies for NCAM (CD56 ; clone $1 \mathrm{~B} 6 ; 1: 50$ dilution, Novocastra Lab., UK) and Smad4 (1: 200 dilution, Santa Cruz Biotechnology, USA) and goat polyclonal antibody of ghrelin that recognizes the mid-portion of ghrelin (1:200 dilution, Santa Cruz Biotechnology). We had prepared for two other types of ghrelin antibody in our study : ghrelin antibodies that recognize either $\mathrm{N}$-terminal or C-terminal of ghrelin (gifts of Prof. K. Kangawa, Department of Biochemistry, National Cardiovascular Center Research Institute, Japan). However, the ghrelin C-terminal antibody gave the same positive reaction as the mid-portion antibody in the mucosa of the stomach and colon/ rectum and the $\mathrm{N}$-terminal antibody gave only a faint reaction in our materials.

After incubation with the primary antibodies, biotinylated link antibody and peroxidase-labeled strep- 
tavidin were applied for $1 \mathrm{~h}$ each at room temperature. Sections were washed thoroughly in phosphate buffer saline (PBS) between each of the procedures. Antigen-antibody complex was detected using $3,3^{\prime}$ diaminobenzidine $/ \mathrm{H}_{2} \mathrm{O}_{2}$ reaction. These slides were counterstained lightly with hematoxylin and mounted for microscopic examination.

We scored the immunoreactivity according to the number of positive cells as well as the intensity of staining of each tumor cell. The number of positive cells was scored as most (more than 50\%), moderate (between $5 \%$ and $50 \%$ ) and a few (less than $5 \%$ ), respectively. The intensity of immunoreactivity was indicated by +++ (strong), ++ (intermediate), and + (faint), respectively. Specificity for ghrelin antibody was evaluated by the absorption test using specific antigen (0.5$5.0 \mu \mathrm{g}$ in $1 \mathrm{~mL}$ of diluted antiserum). NE cells of peritumoral oxyntic gastric mucosa served as positive (internal) control. Negative controls for NCAM and Smad4 were obtained by replacing the primary antibodies by PBS solution.

\section{Statistical analysis}

The Fisher's PLSD test was used to determine the difference in variability level between the distributions of two independent groups. Probability value $\mathrm{p}<0.05$ was considered statistically significant.

\section{RESULTS}

\section{Clinicopathological findings}

Patients with composite NEECs of the stomach were 7 men and 1 woman and the mean age of the patients was 71 yr-old (range : 60-84 yr-old) (Table 1). The tumor size was ranged from 2.0 to $8.0 \mathrm{~cm}$ in diameter with a mean of $4.6 \mathrm{~cm}$. On the other hand, patients with pure NE tumors were 14 men and 7 women and the mean age of the patients was 57 yr-old (range : 34-82 yr-old) (Table2). The tumor size ranged 0.4-4.0 $\mathrm{cm}$ in diameter with a mean of $1.3 \mathrm{~cm}$. Seventeen tumors were less than $2.0 \mathrm{~cm}$ in diameter. Seven of 21 pure NE tumors arose from the foregut, 3 from the midgut and 11 from the hindgut.

\section{Histological findings}

Histologically, composite NEECs of the stomach presented the population composed of different proportion displaying a typical adenocarcinoma pattern with glandular arrangement co-localized with areas arranging in a trabecular and/or solid pattern suggesting NE differentiation. In 5 (Cases 2-4, 6, 7) of 8 composite NEECs, NE components were much larger than adenocarcinoma components and infiltrated through muscularis propia or beyond (Table 1 and Fig. 2). In two cases (Cases 1,8) smaller NE components were observed. In one composite NEEC (Case 5) NE and adenocarcinoma components were equal in size and confined in the submucosa and mucosa, respectively.

Table 1. Clinicopathological characteristics of composite NEEC of stomach

\begin{tabular}{|c|c|c|c|c|c|c|}
\hline \multirow[b]{2}{*}{ No } & \multirow{2}{*}{$\begin{array}{l}\text { Age } \\
\text { (yrs) } \\
\text { Sex }\end{array}$} & \multirow{2}{*}{$\operatorname{Size}(\mathrm{cm})$} & \multicolumn{2}{|c|}{ Histology \& tumor depth } & \multirow{2}{*}{$\begin{array}{c}\mathrm{NE} \\
\text { adenocarcinoma } \\
\text { arrangement }\end{array}$} & \multirow{2}{*}{$\begin{array}{l}\text { Dominant } \\
\text { component }\end{array}$} \\
\hline & & & NE component & $\begin{array}{l}\text { Adenocarcinoma } \\
\text { component }\end{array}$ & & \\
\hline 1 & $78 \mathrm{M}$ & 3.8 & $\operatorname{PDNEC}(\mathrm{sm})$ & WD-AD (sm) & Within $\mathrm{AD}$ & $\mathrm{AD}$ \\
\hline 2 & $74 \mathrm{M}$ & 5.2 & PDNEC(se) & WD-AD (sm) & $\mathrm{AD}$ upon $\mathrm{NE}$ & $\mathrm{NE}$ \\
\hline 3 & $73 \mathrm{M}$ & 2.4 & PDNEC(se) & WD-AD (sm) & $\mathrm{AD}$ upon $\mathrm{NE}$ & $\mathrm{NE}$ \\
\hline 4 & $84 \mathrm{M}$ & 2.0 & PDNEC(mp) & WD-AD (sm) & $\mathrm{AD}$ upon $\mathrm{NE}$ & $\mathrm{NE}$ \\
\hline 5 & $60 \mathrm{~F}$ & 2.8 & PDNEC(sm) & WD-AD (sm) & $\mathrm{AD}$ upon $\mathrm{NE}$ & Even \\
\hline 6 & $62 \mathrm{M}$ & 8.0 & PDNEC(se) & MD-AD (m) & $\mathrm{AD}$ upon $\mathrm{NE}$ & $\mathrm{NE}$ \\
\hline 7 & $69 \mathrm{M}$ & 5.5 & PDNEC(se) & PD-AD (sm) & $\mathrm{AD}$ upon $\mathrm{NE}$ & $\mathrm{NE}$ \\
\hline 8 & $67 \mathrm{M}$ & 7.0 & $\operatorname{PDNEC(na)}$ & WD-AD (se) & na & $\mathrm{AD}$ \\
\hline $9 *$ & $89 \mathrm{~F}$ & 1.6 & PDNEC(mp) & WD-AD (mp) & $\mathrm{AD}$ upon $\mathrm{NE}$ & $\mathrm{NE}$ \\
\hline
\end{tabular}

$\mathrm{M}:$ male, $\mathrm{F}$ : female. PDNEC : poorly differentiated neuroendocrine carcinoma, WD : well differentiated, MD : moderately differentiated, PD : poorly differentiated, NE : neuroendocrine, $\mathrm{AD}$ : adenocarcinoma, na : not available due to lack of tissue sample. sm : submucosa, $\mathrm{mp}$ : muscularis propria, se : serosa.

${ }^{*}$ Composite NEEC of gallbladder 
Table 2. Clinicopathological and immunohistochemical finding of pure NE tumors of gastrointestinal tract

\begin{tabular}{|c|c|c|c|c|c|c|c|}
\hline No & $\begin{array}{c}\text { Age } \\
(\mathrm{yrs}) / \operatorname{Sex}\end{array}$ & Location & Histology & $\begin{array}{l}\text { Size }(\mathrm{cm}) / \\
\text { Invasion }\end{array}$ & NCAM & Ghrelin & Smad4 \\
\hline 10 & $40 \mathrm{M}$ & Stomach & WDNET & $0.9 / \mathrm{sm}$ & Many/++ & Many/+++ & Many/++ \\
\hline 11 & $70 \mathrm{~F}$ & Stomach & WDNET & $0.9 / \mathrm{sm}$ & Few/+ & Few/+++ & Many/+++ \\
\hline 12 & $46 \mathrm{M}$ & Stomach & WDNET & $1.0 / \mathrm{sm}$ & - & Moderate/++ & Moderate/++ \\
\hline 13 & $56 \mathrm{M}$ & Duodenum & WDNET & $1.3 / \mathrm{sm}$ & Many/++ & Many/+ & Many/+++ \\
\hline 14 & $64 \mathrm{M}$ & Duodenum & WDNET & $0.4 / \mathrm{sm}$ & Moderate/++ & Few/+ & Many/++ \\
\hline 15 & $66 \mathrm{M}$ & Duodenum & WDNET & $0.8 / \mathrm{mp}$ & Many/+++ & - & Many/+++ \\
\hline 16 & $63 \mathrm{~F}$ & Appendix & WDNET & $0.4 / \mathrm{sm}$ & Many/+++ & Many/+++ & Many/++ \\
\hline 17 & $34 \mathrm{M}$ & Colon & WDNET & $0.6 / \mathrm{sm}$ & Many/++ & Many/+++ & Many/+++ \\
\hline 18 & $60 \mathrm{M}$ & Rectum & WDNET & $1.0 / \mathrm{sm}$ & - & Many/+++ & Many/++ \\
\hline 19 & $62 \mathrm{M}$ & Rectum & WDNET & $0.9 / \mathrm{sm}$ & Many/+ & Many/+++ & Many/++ \\
\hline 20 & $67 \mathrm{~F}$ & Rectum & WDNET & $0.4 / \mathrm{sm}$ & Many/+ & Many/+++ & Many/+++ \\
\hline 21 & $56 \mathrm{M}$ & Rectum & WDNET & $1.0 / \mathrm{sm}$ & Many/+++ & Moderate/+++ & Many/++ \\
\hline 22 & $61 \mathrm{~F}$ & Rectum & WDNET & $1.0 / \mathrm{mp}$ & Many/+ & Moderate/+++ & Many/+++ \\
\hline 23 & $44 \mathrm{M}$ & Rectum & WDNET & $0.6 / \mathrm{sm}$ & Many/+++ & Many/+++ & Many/+++ \\
\hline 24 & $36 \mathrm{M}$ & Rectum & WDNET & $0.8 / \mathrm{mp}$ & Many/+ & Moderate/++ & Many/+++ \\
\hline 25 & $64 \mathrm{~F}$ & Duodenum & WDNEC & $3.0 / \mathrm{mp}$ & Many/+ & Many/+++ & Many/+++ \\
\hline 26 & $82 \mathrm{M}$ & Ileum & WDNEC & $2.4 / \mathrm{mp}$ & Moderate/+ & Many/+++ & Many/++ \\
\hline 27 & $74 \mathrm{~F}$ & Appendix & WDNEC & $1.3 / \mathrm{mp}$ & Many/+++ & Moderate/++ & Many/++ \\
\hline 28 & $46 \mathrm{~F}$ & Colon & WDNEC & $4.0 / \mathrm{se}$ & Many/+++ & Many/+++ & Few/+ \\
\hline 29 & $39 \mathrm{M}$ & Rectum & WDNEC & $1.8 / \mathrm{sm}$ & Moderate/+++ & Many/+++ & Moderate/+++ \\
\hline 30 & $61 \mathrm{M}$ & Rectum & WDNEC & $2.2 / \mathrm{mp}$ & Many/+ & Many/+++ & Many/+++ \\
\hline
\end{tabular}

$\mathrm{M}:$ male, $\mathrm{F}$ : female. WDNET : well differentiated NE tumor,

WDNEC : well differentiated NE carcinoma. sm : submucosa, mp : muscularis propria, se :

serosa. many : above $50 \%$, moderate : between $5 \%$ and $50 \%$, and few : below $5 \%$ of tumor cells.

,,,$++++++:$ strong, intermediate, faint, and negative, respectively.

All 8 adenocarcinoma components were superficially located and out of 8 adenocarcinoma components 7 cases confined in the mucosa and submucosa and one case (Cases 8 ) infiltrated through muscularis propia or beyond (Fig. 2) (Table 1). Adenocarcinoma components were well-differentiated type in most cases (Fig. 3) except for 2 cases (Cases 6, 7), where moderately and poorly differentiated adenocarcinomas were found. NE components were mostly PDNECs characterized by highly atypical, intermediate-sized cells growing in ill-defined aggregates, often with high mitotic index (Fig. 3). Transitional zone between the two components was observed in all 8 cases but not prominent.

Tumor cells of pure NE tumors were characterized by granular or clear cytoplasm, round to ovoid nuclei with small inconspicuous nucleoli, granular chromatin and minimum to moderate pleomorphism. The cells grew in nests, clusters or trabeculae, occasionally forming tubular or pseudo-glandular structures (Fig. 4). We divided the pure $21 \mathrm{NE}$ tumors into two categories, WDNETs and WDNECs, on the basis of the size and the depth of the tumor according to the WHO classification (2) (Table 2). There were 15 WDNETs and 6 WDNECs. In WDNETs mitoses was $<2 / 10$ highpower-field (HPF), while WDNECs had a moderately elevated mitotic index $(>2 / 10 \mathrm{HPF})$. 


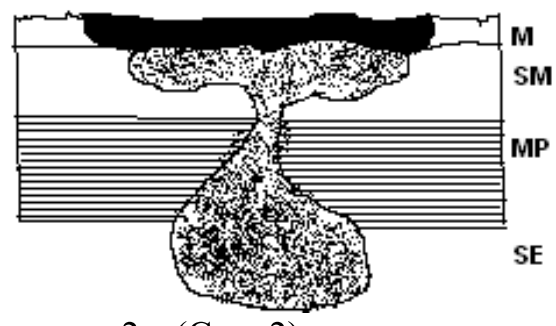

2 a (Case 2)

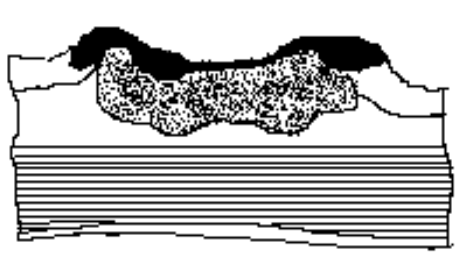

$2 \mathrm{~b}($ Case 5)

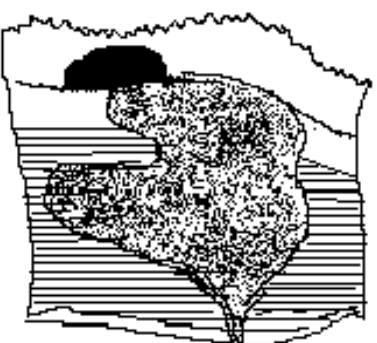

2 c (Case 6)

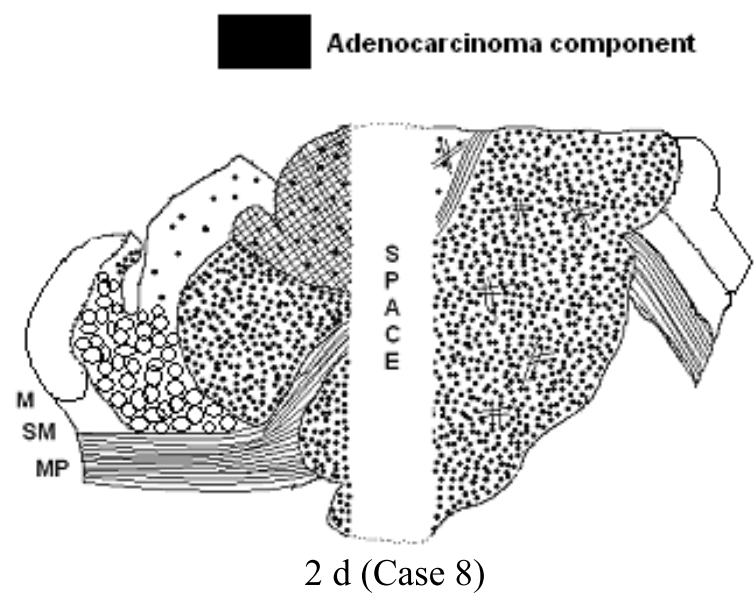

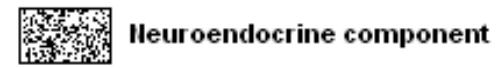

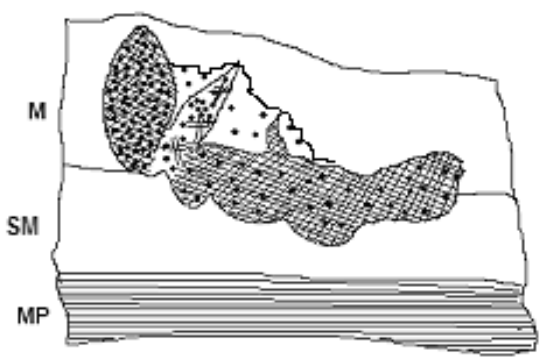

2 e (Case 1)

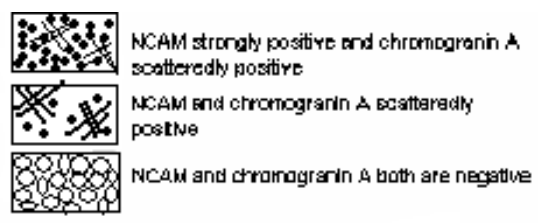

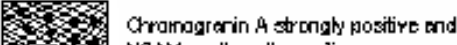
NCAM scotteredly postiye

Fig.2. Schematic diagram of composite NEECs. Figures 2a-2c show the topological relationship of adenocarcinoma component and NE components in the representative slide. Figures $2 \mathrm{~d}$ and $2 \mathrm{e}$ show two exceptional composite NEECs in terms of NCAM expression. M : mucosa, SM : submucosa, MP : muscularis propria and SE : serosa.

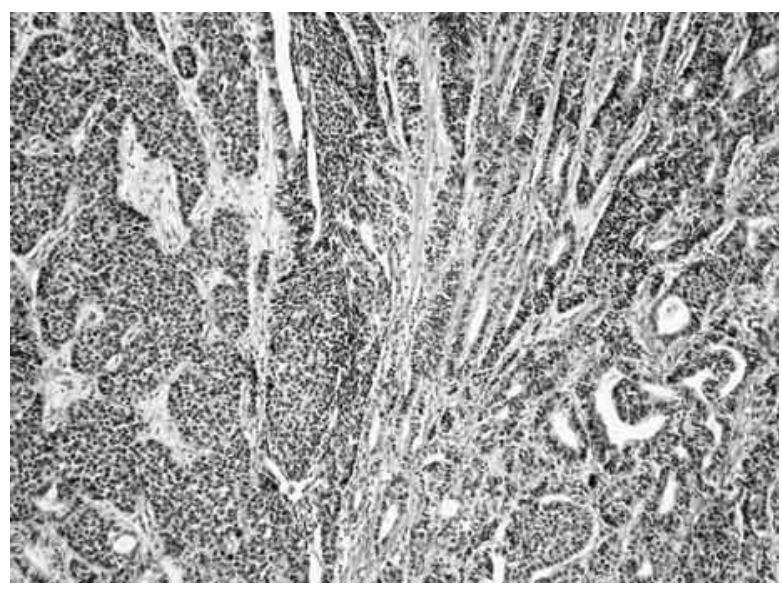

Fig.3. Composite NEEC (Case 1). Well differentiated adenocarcinoma component (right) and NE component (left) are located side-by-side. The latter component is composed of small, poorly differentiated cells with scanty cytoplasm.

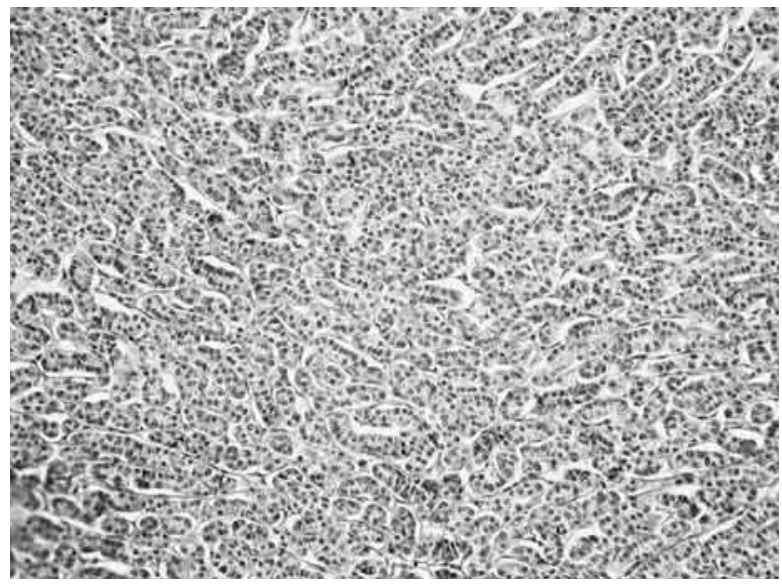

Fig.4. Pure NE tumor (WDENET) of the stomach (Case 12). Tumor is composed of trabeculae-like structures of small, round cells with round-to-oval nuclei. 


\section{Immunohistochemical findings in normal tissues}

Normal superficial epithelial cells and crypts adjacent to NE tumors showed no immunoreactivity for NCAM. However, a few cells in deep glands were positive for NCAM only in the stomach of the body and antrum and the duodenum but not in the intestine, colon or rectum (Fig. 5a). These NCAM-immunoreactive cells seemed to be not only NE cells but also non-NE cells. A few ghrelin-immunoreactive cells were found in normal deep glands of the stomach and duodenum but not in the superficial epithelium (Fig. 5b). Strong to intermediate immunoreactivity for $\operatorname{Smad} 4$ was found in normal epithelium and crypts of the entire GI tract. The immunostaining was completely disap-
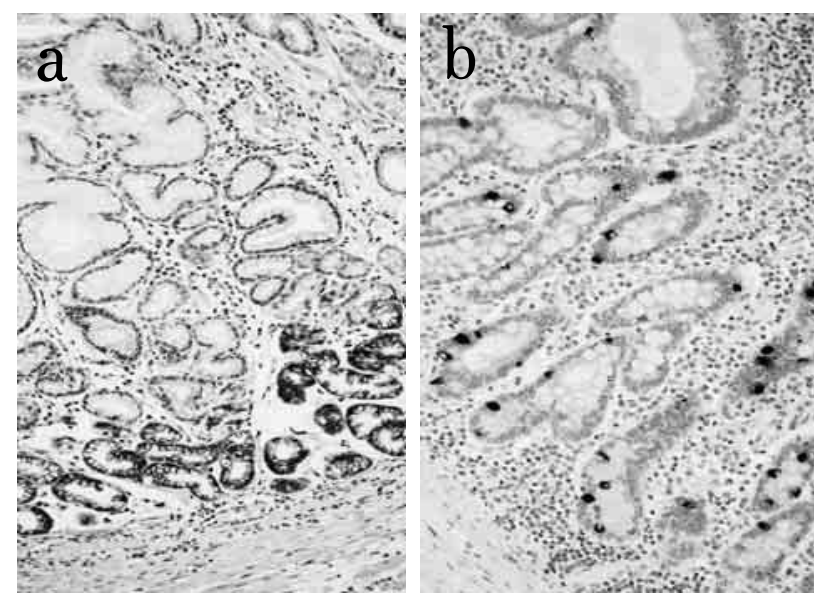

Fig.5. a) Immunohistochemical expression of NCAM in normal gastric mucosa. NCAM-positive cells are observed in deep glands. b) Ghrelin in normal gastric mucosa. A substantial number of ghrelin-positive cells are noted. peared after absorbing by the specific ghrelin antigen and the tissue sections led to negative immunoreactivity in the absence of NCAM and Smad4 antibodies.

\section{Immunohistochemical findings in composite NEECs}

Immunohistochemical findings of 8 composite NEECs of the stomach are summarized in Table 3.

\subsection{NCAM}

In 5 (62.5\%) of 8 composite NEECs, NE components showed immunoreactivity for NCAM, which was mostly membranous (Table 4) (Fig. 6). The number and the intensity of immunoreactive cells were varied from case to case ; four cases showed immunoreactivity in most tumor cells (Table 3). Out of these 5 NCAMpositive NE components, 3 cases (Cases 2, 5,7) showed homogeneous NCAM expression all over the areas. Adenocarcinoma components of these 3 composite NEECs showed no immunoreactivity for NCAM (Fig. 6). On the other hand, in the remaining 2 cases (Cases $1,8)$ NCAM expression was different from the above cases and unique. In Case 1, NCAM was found homogeneously positive in one half area of NE component and the other half contained only a few NCAM-positive cells (Fig. 2), although CgA was positive in all cells of $\mathrm{NE}$ component. In CgA-negative adenocarcinoma component of the same case, NCAM-immunoreactive cells were occasionally found. In Case 8, CgA-positive NE component showed NCAM immunoreactivity in many cells and adenocarcinoma component showed a heterogeneous NCAM immunoreactivity; the larger part of this tumor presented no immunoreactivity

Table 3. Expression of NCAM, ghrelin and Smad 4 in composite NEEC

\begin{tabular}{|c|c|c|c|c|c|c|}
\hline \multirow{2}{*}{$\begin{array}{l}\text { Case } \\
\text { No. }\end{array}$} & \multicolumn{2}{|c|}{ NCAM } & \multicolumn{2}{|c|}{ Ghrelin } & \multicolumn{2}{|c|}{ Smad4 } \\
\hline & NE comp. & $\begin{array}{c}\text { Adenoca. } \\
\text { comp. }\end{array}$ & NE comp. & $\begin{array}{c}\text { Adenoca. } \\
\text { comp. }\end{array}$ & $\begin{array}{c}\mathrm{NE} \\
\text { comp. }\end{array}$ & $\begin{array}{c}\text { Adenoca. } \\
\text { comp. }\end{array}$ \\
\hline 1 & Moderate/+* & \pm & Many/+++ & - & Few/+ & Many/++ \\
\hline 2 & Many/++** & - & Many/++ & - & Many/++ & Many/++ \\
\hline 3 & - & - & - & - & - & - \\
\hline 4 & - & - & - & - & Few/+ & Many/+ \\
\hline 5 & Many/+++** & - & - & \pm & Many/+++ & Many/+++ \\
\hline 6 & - & - & - & - & Many/++ & Many/++ \\
\hline 7 & Many/++** & - & Few/+ & \pm & Moderate/++ & Moderate/++ \\
\hline 8 & Many/++* & Moderate/++ ${ }^{*}$ & Few/+ & - & Many/+ & Few/+ \\
\hline $9 * * *$ & Many/+++ & - & na & na & Many/+++ & Many/+++ \\
\hline
\end{tabular}

$\mathrm{NE}$ : neuroendocrine, adenoca : adenocarcinoma, comp : component.

Many : above $50 \%$, moderate : between $5 \%$ and $50 \%$ and few : below $5 \%$ of tumor cells, \pm : very few. ${ }^{+++},++,+,-$: strong, intermediate, faint, and negative, respectively

*heterogeneous, ${ }^{*}$ homogeneous, ${ }^{* * *}$ composite NEEC of gallbladder. na : not available 
Table 4. Expression of NCAM, ghrelin and Smad4 in composite NEEC and pure NE tumor

\begin{tabular}{|c|c|c|c|c|c|}
\hline \multirow{2}{*}{} & \multicolumn{2}{|c|}{ Composite NEEC (8) } & \multicolumn{2}{c|}{ Pure NE tumor(21) } \\
\cline { 3 - 6 } & NE comp. & Adenoca. comp. & WDNET(15) & WDNEC(6) \\
\hline \multirow{2}{*}{ NCAM $^{\mathrm{a}}$} & Homogeneously positive & $3(37.5 \%)$ & 0 & $13(86.7 \%)$ & $6(100.0 \%)$ \\
\cline { 2 - 6 } & Positive in total & $5(62.5 \%)$ & $2(25.0 \%)^{*}$ & $13(86.7 \%)$ & $6(100.0 \%)$ \\
\hline \multirow{2}{*}{ Ghrelin $^{\mathrm{b}}$} & $4(50.0 \%)$ & $2(25.0 \%)^{* *}$ & $14(93.3 \%)$ & $6(100.0 \%)$ \\
\hline Smad4 & $7(87.5 \%)$ & $7(87.5 \%)$ & $15(100 \%)$ & $6(100.0 \%)$ \\
\hline
\end{tabular}

NEEC : neuroendocrine-exocrine carcinoma, NE : neuroendocrine, Adenoca : adenocarcinoma, comp : component, WDNET : well differentiated neuroendocrine tumor, WDNEC : well differentiated neuroendocrine carcinoma.

* One of them showed immunoreactivity in a few tumor cells.

$* *$ Immunoreactivity in a few tumor cells.

a $P<0.05$, NE components of NEECs $v s$. pure NE tumors

${ }^{\text {b }} P<0.05$, NE components of NEECs $v s$. pure NE tumors

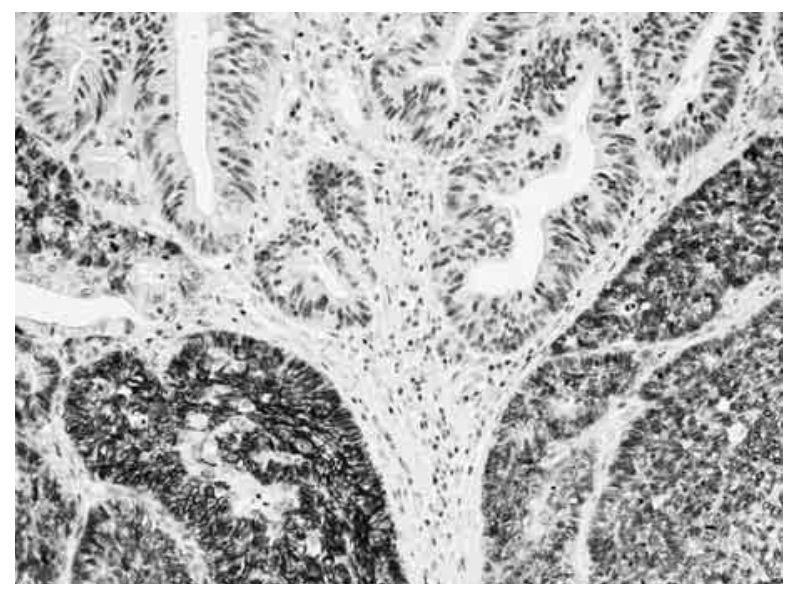

Fig.6. NCAM in composite NEEC (Case5). Note that NCAM is positive in NE component (below) and negative in adenocarcinoma component (above).

for NCAM, while a smaller part showed either partially homogeneous or partially scattered immunoreactivity for NCAM (Fig. 2). In 3 of 8 composite NEECs, both $\mathrm{NE}$ and adenocarcinoma components were negative for NACM.

\section{2. Ghrelin}

Ghrelin showed immunoreactivity in NE components of 4 (50.0\%) of 8 composite NEECs (Table 4) (Fig. 7). The number of immunoreactive cells was more than $50 \%$ of tumor cells in two cases (Cases 1,2) but a few in other two cases (Cases 7, 8). Adenocarcinoma components of 2 composite NEECs (Cases 5 , 7) also showed immunoreactivity for ghrelin in a few cells (Table 3) (Fig. 8).

\section{3. Smad4}

Among 8 composite NEECs, 7 (87.5\%) NE components and respective adenocarcinoma components

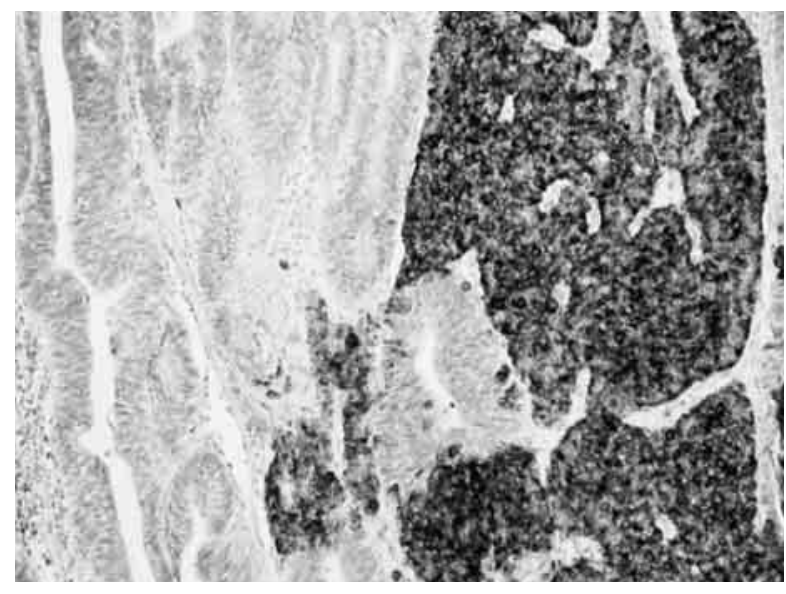

Fig.7. Ghrelin in composite NEEC (Case1). Ghrelin is expressed strongly in NE component (right) and negative in adenocarcinoma component (left).

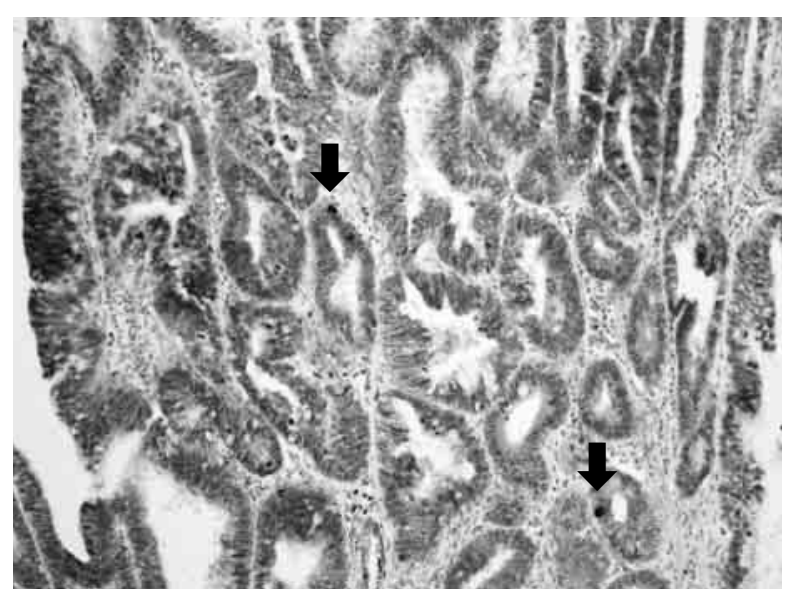

Fig.8. Ghrelin in adenocarcinoma component of composite NEEC (Case 5). Ghrelin is expressed in a few cells (arrows). 
showed immunoreactivity for Smad4 (Table 4). The pattern of immunoreactivity for Smad4 was mostly combined nuclear and cytoplasmic, which was same as normal epithelium (Fig. 9).

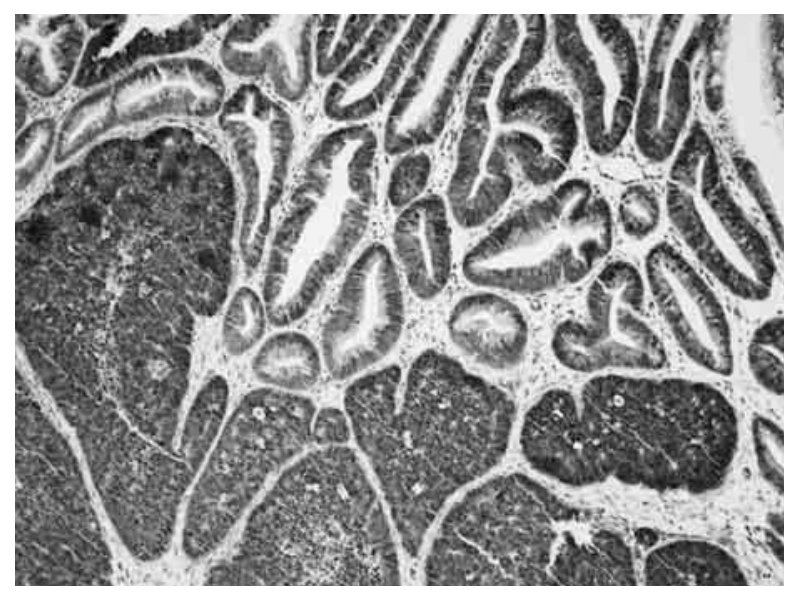

Fig.9. Smad4 in composite NEEC (Case5). Smad4 is positive in both $\mathrm{NE}$ and adenocarcinoma components of the tumor.

\section{Immunohistochemical findings in pure NE tumors}

Immunohistochemical findings of 21 pure NE tumors are summarized in Table 2.

\section{1. NCAM}

NCAM immunoreactivity was found in 19 (90.5\%) of 21 pure NE tumors including 13 of 15 WDNETs and all 6 WDNECs (Table 2). The pattern of NCAM immunoreactivity was mainly membranous and in occasionally cytoplasmic. NCAM positive cells were evenly distributed throughout the tumor tissue (homogeneous pattern). Among these 19 pure NE tumors, 78.9\% of cases showed NCAM immunoreactivity in more than $50 \%$ cells of each tumor (Fig. 10). No significant difference in NCAM immunoreactivity was found among different anatomical sites.

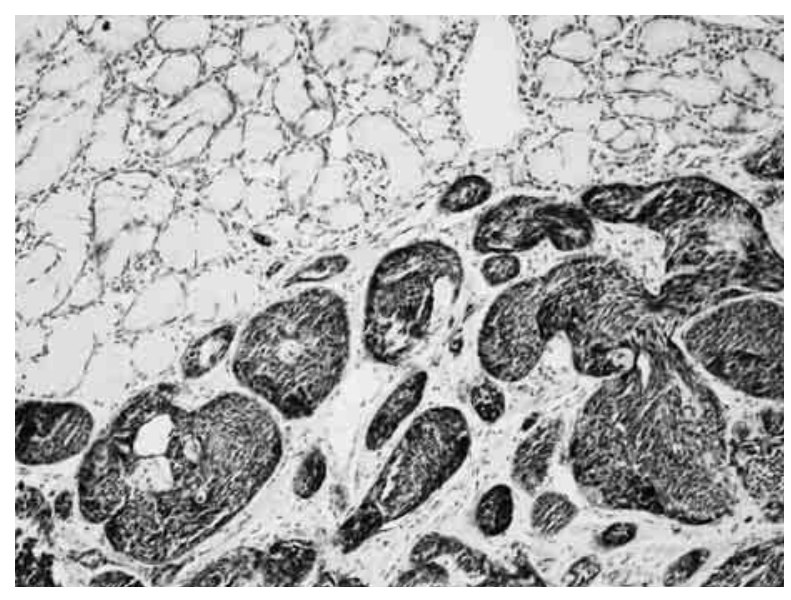

Fig.10. NCAM in WDNET of the duodenum (Case 15). Many tumor cells are immunoreactive for NCAM.

\section{2. Ghrelin}

Ghrelin immunoreactivity was found in all but one (95.2\%) of pure NE tumors of the GI tract including 14 of 15 WDNETs and all 6 WDNECs examined (Table 2). The pattern of ghrelin immunoreactivity was cytoplasmic (Fig. 11). Among these 20 pure NE tumors, $65 \%$ of cases showed positive immunoreactivity in more than $50 \%$ cells of each tumor (Fig. 11). No significant difference in ghrelin immunoreactivity was found among different anatomical sites.

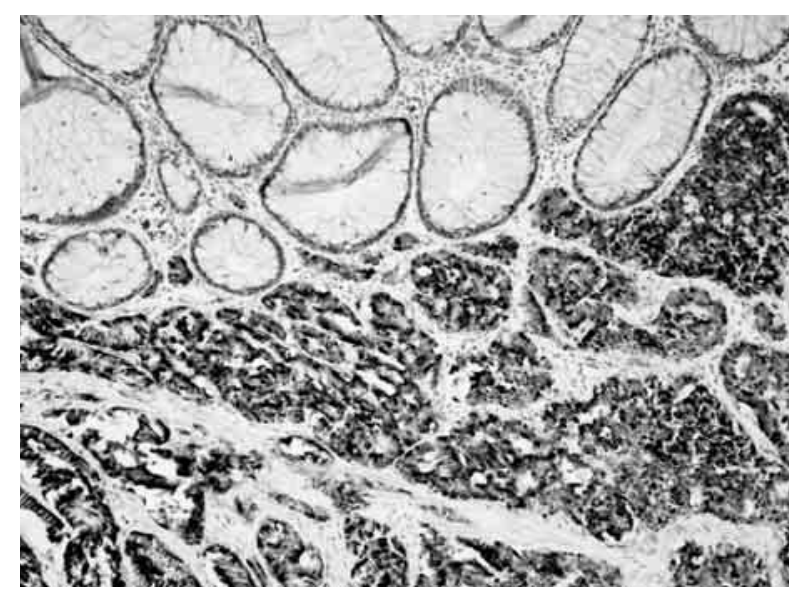

Fig.11. Ghrelin in WDNET of the rectum (Case 24). Ghrelin is moderately expressed in this WDNET.

\section{3. Smad4}

All 21 pure NE tumors examined showed positivity for Smad4 (Table 2).

\section{Composite NEEC of the gallbladder}

In the composite NEEC of the gallbladder (Case 9), $\mathrm{NE}$ component occupied a vast majority of the tumor and well differentiated adenocarcinoma was restricted only in a small area of the mucosa of the gallbladder. $\mathrm{NE}$ component invaded into the liver and occupied the subtotal liver tissue. Immunohistochemically, NCAM was strongly positive in most cells of NE component while negative in adenocarcinoma component. Ghrelin immunoreactivity was not examined due to the lack of tissue. Smad4 showed a strong immunoreactivity both in NE and adenocarcinoma components. Normal epithelial tissue was negative for NCAM and ghrelin (Table 3).

\section{DISCUSSION}

To our knowledge, there has been no report of NCAM expression in composite NEECs of the gastrointes- 
tinal tract in English journals. In this study NE components in 5 (62.5\%) of 8 composite NEECs expressed NCAM immunoreactivity either homogeneously (in 3 cases) or heterogeneously (in 2 cases). On the other hand, almost all pure NE tumors expressed NCAM immunoreactivity, which was homogeneously demonstrated in most tumor cells. A significant difference in homogeneous NCAM expression was noted between NE components of composite NEECs and pure NE tumors ( $37.5 \%$ and $90.5 \%$, respectively, $\mathrm{p}<0.05$ ), although no significant difference in NCAM expression was observed among the anatomical tumor sites or between histologic subtypes of pure NE tumors. It has been well known that NCAM is an excellent marker for all types of NE tumors including WDNETs (such as carcinoid tumors) and PDNECs (such as small cell carcinomas) of the lung (23-25), and thus the expression of NCAM seems to be independent of the degree of $\mathrm{NE}$ differentiation of tumors. Therefore, lower expression of NCAM in NE components of composite NEECs is unlikely caused by poor differentiation of the tumors.

Among 5 composite NEECs with NCAM-positive NE components, 3 tumors were uniformly positive for NCAM in NE components and negative for NCAM in adenocarcinoma components, showing a remarkable difference between the two components and suggesting a clonal expansion of the tumor cells with NE differentiation.

It is noteworthy that $\mathrm{NE}$ components of 3 composite NEECs (Cases 3, 4,6) were totally negative for NCAM although NE differentiation was evident by $\mathrm{CgA}$ immunoreactivity. This indicates that tumor cells in these NE components may be different from those in pure NE tumors of the GI tract in their NE property. To the contrast, 2 composite NEECs (Cases 1and 8) showed positive NCAM expression in either scattered or clustered cells of adenocarcinoma components. These 2 tumors were also immunoreactive for NCAM in NE components heterogeneously but not homogeneously. Of interest, in one case (Case 8) a few adenocarcinoma components growing in a solid pattern suggestive of NE differentiation showed a strong immunoreactivity for NCAM whereas the other parts growing in a glandular or cord-like pattern were negative for NCAM. NCAM expression has been demonstrated focally or heterogeneously in ordinary adenocarcinomas arising in various sites including the GI tract, lung, pancreas, breast and billiary tract (26-30). The role of NCAM in such ordinary adenocarcinomas is not known $(29,31)$. Nonetheless, several studies suggested that 1) NCAM may appear in the earliest stage of carcinoma (34), 2) these tumors may repre- sent transition between non-NE tumor and NE tumor (32), and 3) it may be non-specific likely in relation with cross-reaction with an unidentified intracellular glycoprotein present in mucinous adenocarcinoma (33).

Ghrelin showed positive immunoreactivity in $95.2 \%$ in pure NE tumors of the GI tract regardless of their anatomic sites consistent with those reported previously. Pappoti et al . showed that $75 \%$ of gastric NE tumors and $27 \%$ of intestinal NE tumors were immunoreactive for ghrelin (17). Rindi et al. also reported that ghrelin-immunoreactivity was seen in $76 \%$ of well differentiated gastric NE tumors although they did not find ghrelin-immunoreactive cells in intestinal NE tumors (16). The two studies used anti-ghrelin antibody that recognized the mid- to C-terminal of ghrelin (13-28 sequence) and we also used the antibody that recognized mid-portion of ghrelin. In our preliminary study using another anti-ghrelin antibody that recognized the N-terminal of ghrelin, only $21.7 \%$ of the pure NE tumors showed ghrelin immunoreactivity (data not shown). It is of note that there would be a great difference in ghrelin immunoreactivity in NE tumors depending on the type of antibody used.

There has been no report on ghrelin immunoreactivity in gastric composite NEECs so far. Our study revealed that ghrelin was positive in 4 of $8 \mathrm{NE}$ components and 2 adenocarcinoma components and only a small number of positive cells were noted in $2 \mathrm{NE}$ components and 2 adenocarcinoma components among ghrelin-positive tumors. A significantly lower incidence of ghrelin immunoreactivity in gastric composite NEECs than pure NE tumors ( $50.0 \%$ vs. $95.2 \%, \mathrm{p}<0.05)$ may be partly due to the difference in NE differentiation. Rindi et al. reported that ghrelin immunoreactivity was not seen in poorly differentiated NE tumors of the stomach (16).

Smad4 showed positive immunoreactivity in $87.5 \%$ of NE and adenocarcinoma components of composite NEECs and in all pure NE tumors examined. Thus, Smad4 showed no significant difference in expression between composite NEECs and pure NE tumors. Smad4 has been known to be involved in the tumorigenesis of exocrine tumors such as pancreatic, gastric and colorectal adenocarcinomas as one of tumor suppressor genes $(18,19)$. On the other hand, the role of Smad4 on NE tumors is yet to be clarified. In previous studies, Smad4 expression was found in NE tumors of the GI tract, pancreas and extrahepatic bile duct (20-22, 34). Two recent studies on NE tumors of pancreas showed different expression of Smad4. One study by Bartsch et al. showed that Smad4 mutation and ho- 
mozygous deletions were observed in 55\% of NE tumors of pancreas (35), whereas Smad4 inactivation by mutation or deletion was very rare in the second study by Perren et al. (20). The present immunohistochemical study implies that the role of Smad4 on tumorigenesis may be minimum for both gastric composite NEECs and pure NE tumors of GI tract.

It has been claimed that the tumorigenesis of pure NE tumors, especially of well differentiated type, and that of NE components of composite NEECs are different to each other. Most pure NE tumors may originate from the cell foredoomed to differentiate to $\mathrm{NE}$ cell $(7,36)$. On the other hand, as for the histogenesis of composite NEECs there are two known hypothesis : 1) simultaneous proliferation of different lines of cells, non-NE cells and NE cells, and 2) proliferation of pluripotent precursor cells capable of differentiation along adenocarcinomas or NE tumors (811, 37-39). In our study, the presence of transitional zone argues against of a collision tumor of our cases. The topographical relationship of the two components within a composite NEEC may be an indicative point of the histogenesis of the tumor. The two components are likely to be influenced by both temporal relationship and growth potential of dual differentiation (40). In the present study, most of composite NEECs were composed of superficially located, smaller, well differentiated adenocarcinoma component and juxtaposed, larger NE component at the deeper part of the tumor. Transitional zone between the two components was observed practically in all our cases although not prominent. These findings are consistent with previous studies showing that the adenocarcinoma components were mostly located in the mucosa and submucosa and that the NE components were in the deeper part of the gastric wall (6, 10, 40-42). In addition, Kim et al. performed a genetic study of gastric composite NEECs and found that 6 of 8 cases showed a primary loss of heterozygosity which was shared by both adenocarcinoma and NE components and a secondary loss of heterozygosity or mutation that were restricted in $\mathrm{NE}$ components, irrespective of the tumor size (40). They suggested that most of gastric composite NEECs were sequentially evolved from a glandular precursor to a genetically heterogeneous adenocarcinoma and then to NE carcinoma (40). The morphological and immunohistochemical findings in our study also suggest that NE components in 6 of 8 gastric composite NEECs may develop from a precursor cell of the early-stage adenocarcinoma and subsequently show a clonal expansion of NE tumor cells resulting in a mass identifiable as NE carcinoma. This hypothesis may be ap- plied not only to composite NEECs of the stomach but also to those of other organs, because similar histological and immunohistochemical findings were observed in a case arising in the gallbladder (Case 9).

The remaining two cases of gastric composite NEECs reported by Kim et al. reciprocally lost different allele of identical loci on multiple chromosomes, suggesting a dual differentiation concurrently arising from a single precursor (40). Similarly, in our two cases (Cases 1 and 8), smaller NE components were found heterogeneously within the adenocarcinoma components and side-by-side, suggesting that these components may be from a pluripotent epithelial cell. Similar hypothesis was also proposed by Vortmeyer et al., who suggested that poorly differentiated colorectal NE carcinomas associated with adenocarcinomas were most likely derived from either a pluripotent epithelial stem cell or an adenocarcinoma precursor cell (43).

In summary, the present morphological and immunohistochemical study, taken together with the previous findings, indicates that $\mathrm{NE}$ components of composite NEECs may have different NE property and tumorigenesis from pure NE tumors and that most composite NEECs may originate from an adenocarcinoma precursor cell while occasional tumors from a pluripotent epithelial cell. NCAM may have some role in $\mathrm{NE}$ differentiation in more than half of $\mathrm{NE}$ components of NEECs. We believe that better description and identification of composite NEECs may lead to better recognition of distinct clinical behavior of NE tumors arising in the GI tract.

\section{ACKNOWLEDGEMENTS}

We would like to express our sincere thanks to Prof. K. Kangawa (Department of Biochemistry, National Cardiovascular Center Research Institute, Osaka, Japan) for providing us the ghrelin antibodies that recognize either N-terminal or C-terminal of ghrelin and also to Ms. N. Amo and E. Hisamoto for their kind technical assistance.

\section{REFERENCES}

1. Lewin $\mathrm{K}$ : Carcinoid tumors and the mixed (composite) glandular-endocrine cell carcinomas. Am J Surg Pathol 11(suppl) : 71-86, 1987

2. Solcia E, Kloppel G, Sobin LH : Histological typing of neuroendocrine tumors. International histological classification of tumors. World Health 
Organization, Berlin Heidelberg New York, 2000

3. Capella C, Rosa SL, Uccella S, Billo P, Carnaggia M : Mixed endocrine-exocrine tumors of the gastrointestinal tract. Semin Diag Pathol 17 : 91-103, 2000

4. Azzopardi JG, Pollock DJ : Argentaffin and argyrophil cells in gastric carcinoma. J Pathol Bacterol 86 : 443-451, 1963

5. Ooi A, Mai M, Ogino T, Ueda H, Kitamura T, Takahashi Y, Kawahara E, Nakanishi I : Endocrine differentiation of gastric adenocarcinoma. The prevalence as evaluated by immunoreative chromogranin A and its biologic significances. Cancer $62: 1092-1104,1988$

6. Matsui K, Kitagawa M, Miwa A, Kuroda Y, Tsuji M:Small cell carcinoma of the stomach : A clininicopathological study of 17 cases. Am J Gastrienterol 86 : 1167-1175, 1991

7. Soga J, Tazawa K, Aizawa O, Wada K, Tuto T : Argentaffin cell adenocarcinoma of stomach : An atypical carcinoid ? Cancer 28 : 999-1003, 1971

8. Murayama H, Imai T, Kikuchi M : Solid carcinomas of the stomach. A combined histological, light and electron microscopic study. Cancer $51: 1673-1681,1983$

9. Yamashina M, Flinner RA : Concurrent occurrence of adenocarcinoma and carcinoid tumor of stomach. A composite tumor or collision tumors? Am J Clin Pathol 83 : 233-236, 1985

10. Cruso ML, Pilato FP, D'adda T, Baggy MT, Fucci L, Valentini AM, Lacatena M, Bordi Cesare : Composite carcinoid-adenocarcinoma of the stomach associated with multiple gastric carcinoids and nonantral atrophy. Cancer 64 : 1534-1539, 1989

11. Yang GC, Rotterdam H : Mixed (composite) glandular-endocrine cell carcinoma of the stomach. Report of a case and review of the literature. Pathol 15 : 592-598, 1991

12. Rassidakis GZ, Delladetsima JK, Letsos SP, Polyzos A, Yannopoulos A: Hepatoid adenocarcinoma of the stomach with extensive neuroendocrine differentiation and a coexisting carcinoid tumour. Histopathology 33 : 186-188, 1998

13. Cavallaro U, Christofori G: Cell adhesion in tumor invasion and metastasis : Loss of the glue is not enough. Biochim Biophys Acta 1552 : $39-45,2001$

14. Huerta S, Srivatsan ES, Venkatesan N, Peters J, Moatamed F, Renner S, Livingston EH : Alternative mRNA splicing in colon cancer causes loss of expression of neural cell adhesion molecule.
Surgery $130: 834-843,2001$

15. Roesler J, Srivatsan E, Moatamed F, Peters J, Livingston $\mathrm{EH}$ : Tumor suppressor activity of neural cell adhesion molecule in colon carcinoma. Am J Surg 174 : 251-257, 1997

16. Rindi G, Savio A, Torsello A, Michele Z, Locatelli V, Cocchi D, Paolotti D, Solcia E : Ghrelin expression in gut endocrine growths. Histochem Cell Biol 117 : 521-525, 2002

17. Papotti M, Cassoni P, Volante M, Deghenghi R, Muccioli G, Ghigo E: Ghrelin producing endocrine tumors of the stomach and intestine. J Clin Endocrinol Metab 86 : 5052-5059, 2001

18. Hahn SA, Hoque AT, Moskaluk CA, da Costa LT, Schutte M, Rozenblum E, Seymour AB, Weinstein CL, Yeo CJ, Hruban RH, Kern SE: Homozygous deletion map at $18 \mathrm{q} 21.1$ in pancreatic cancer. Cancer Res 56 : 490-494, 1996

19. Hahn SA, Schutte M, Hoque AT, Moskaluk CA, da Costa LT, Rozenblum E, Weinstein CL, Fischer A, Yeo CJ, Hruban RH, Kern SE : DPC4, a candidate tumor suppressor gene at human chromosome 18 q 21.1. Science $271: 350-353$, 1996

20. Perren A, Saremaslani P, Schmid S, Bonvin C, Locher T, Roth J, Roth J, Heitz PU, Komminoth P : DPC4/Smad4 : no mutations, rare allelic imbalances, and retained protein expression in pancreatic endocrine tumors. Diagn Mol Pathol 12 : 181186, 2003

21. Lollgen RM, Hessman O, Szabo E, Westin G, Akerstrom G: Chromosome 18 deletions are common events in classical midgut carcinoid tumors. Int J Cancer $92: 812-815,2001$

22. Scarpa A, Orlandini S, Moore PS, Lemoine NR, Beghelli S, Baron A, Falconi M, Zamboni G:DPC4 is expressed in virtually all primary and metastatic pancreatic endocrine carcinomas. Virchows Arch 440 : 155-159, 2002

23. Lantuejoul S, Moro D, Michalides RJ, Brambilla C, Brambilla E : Neural cell adhesion molecules (NCAM) and NCAM-PSA expression in neuroendocrine lung tumors. Am J Surg Pathol 22 : 12671276, 1998

24. Kibbelaar RE, Moolenaar KE, Michalides RJ, Van Bodegom PC, Vanderschueren RG, Wagenaar SS, Dingemans KP, Bitter-Suermann D, Dalesio O, Van Zandwijk N, Mooi WJ : Neural cell adhesion molecule expression, neuroendocrine differentiation and prognosis in lung carcinoma. Eur J Cancer 27 : 431-435, 1991

25. Aletsee-Ufrecht MC, Langley K, Rotsch M, 
Havemann K, Gratzl M. NCAM : a surface marker for human small cell lung cancer cells. FEBS Lett 267 : 295-300, 1990

26. Nguyen VN, Mirejovsky T, Melinova L, Mandys V : CD44 and its v6 spliced variant in lung carcinomas : relation to NCAM, CEA, EMA and UP1 and prognostic significance. Neoplasma 47: 400408, 2000

27. Tezel E, Nagasaka T, Nomoto S, Sugimoto H, Nakao A : Neuroendocrine-like differentiation in patients with pancreatic carcinoma. Cancer 89 : 2230-2236, 2000

28. Seki H, Koyama K, Tanaka J, Sato Y, Umezawa A: Neural cell adhesion molecule and perineural invasion in gallbladder cancer. J Surg Oncol 58: 97-100, 1995

29. Zoltowska A, Stepinski J, Lewko B, Serkies K, Zamorska B, Roszkiewicz A, Lzycka-Swieszewska E, Kruszewski WJ : Neural cell adhesion molecule in breast, colon and lung carcinomas. Arch Immunol Ther Exp (Warsz) 49 : 171-174, 2001

30. Asayama Y, Aishima S, Taguchi K, Sugimachi K, Matsuura S, Masuda K, Tsuneyoshi M : Coexpression of neural cell adhesion molecules and bcl-2 in intrahepatic cholangiocarcinoma originated from viral hepatitis : relationship to atypical reactive bile ductule. Pathol Int 52 : 300-306, 2002

31. Kenmotsu M, Gouchi A, Maruo Y, Murashima N, Hiramoto $\mathrm{Y}$, Iwagaki $\mathrm{H}$, Orita $\mathrm{K}$ : [The expression of neural cell adhesion molecule (NCAM), neural invasion and recurrence patterns in rectal cancer-a study using anti-NACM (neural cell adhesion molecule) antibody] Nippon Geka Gakkai Zasshi 95 (in Japanese) : 66-70, 1994

32. Brezicka FT, Olling S, Bergman B, Berggren H, Engstrom CP, Hammarstrom S, Holmgren J, Larsson S, Lindholm L: Coexpression of ganglioside antigen Fuc-GM1, neural-cell adhesion molecule, carcinoembryonic antigen, and carbohydrate tumor-associated antigen CA 50 in lung cancer. Tumour Biol 13 : 308-315, 1992

33. Lantuejoul S, Laverriere MH, Sturm N, Moro D,
Frey G, Brambilla C, Brambilla E : NCAM (neural cell adhesion molecules) expression in malignant mesotheliomas. Hum Pathol 31 : 415-421, 2000

34. Maitra A, Krueger JE, Tascilar M, Offerhaus GJ, Angeles-Angeles A, Klimstra DS, Hruban RH, Albores-Saavedra J : Carcinoid tumors of the extrahepatic bile ducts : a study of seven cases. Am J Surg Pathol 24 : 1501-1510, 2000

35. Bartsch D, Hahn SA, Danichevski KD, Ramaswamy A, Bastian D, Galehdari H, Barth, P, Schmiegel W, Simon B, Rothmund M : Mutations of the DPC4/ Smad4 gene in neuroendocrine pancreatic tumors. Oncogene 18 : 2367-2371, 1999

36. Lundwvist $\mathrm{M}$, Wilander $\mathrm{E}$ : Exocrine and endocrine differentiation in small intestinal adenocarcinomas. Arch Pathol Micrib Scand Sect A 91 : 469-474, 1983

37. Adhikari D, Conte C, Eskreis D, Urmacher C, Ellen K: Combined adenocarcinoma and carcinoid tumor in atrophic gastritis. Ann Clin Lab Sci $32: 422-427,2002$

38. Lyda M, Fenoglio-preiser CM : Adenoma-carcinoid tumors of the colon. Arch Pathol lab Med 122 : 262-265, 1998

39. Lattes R, Grossi C: Carcinoid tumors of the stomach. Cancer 9 : 698-711, 1956

40. Kim KM, Kim MJ, Cho BK, Choi SW, Rhyu MG : Genetic evidence for the multi-step progression of mixed glandular-neuroendocrine gastric carcinomas. Virchows Arch 400 : 85-93, 2002

41. Wheeler DA, Chandrasoma P, Carriere CA, Schwinn CP : Cytologic diagnosis of gastric composite adenocarcinoma-carcinoid. Acta Cytol 28 : 706-708, 1983

42. Bates HR, Belter LF : Composite carcinoid tumor (argentaffinoma-adenocarcinoma) of the colon. Dis Colon Rectum 10 : 467-470, 1967

43. Vortmeyer AO, Lubensky IA, Merino MJ, Wang CY, Pham T, Furth EE, Zhuang Z:Concordance of genetic alteration in poorly differentiated colorectal carcinomas and associated adenocarcinomas. J Natl Cancer Inst 89 : 1448-1453, 1997 